\title{
Dancing Practice Teaching and Thinking of Art Education Major
}

\author{
Qian Wang \\ School of Dance, Nanjing University of the Arts, Nanjing 210000, Jiangsu, China \\ Email: 1050047852@qq.com
}

\begin{abstract}
Dance practice teaching is an important way for college art education students to broaden their knowledge horizons and improve their overall artistic quality. At present, dance practice teaching still faces some practical problems and difficulties in teaching design, teaching methods and teaching ability. In the future, dance practice teaching should continuously optimize teaching goals and plans, innovate teaching models, and further enhance the professional practice teaching capabilities of dance teachers.
\end{abstract}

Keywords: dance, practice teaching, thinking, countermeasures

The stage art practice of dance is an important content of art education professional practice courses in art colleges and universities, and an important reference index for improving students' artistic quality and testing teaching results. From the art theory class to the stage of art practice performance, for students majoring in art education, it is a leap in knowledge learning and improvement of ability, and it has a strong interest and attraction to students. At present, the arrangement of dance practice classes for the art education major of Nanjing University of the Arts is mainly based on the physical training of Western classical ballet, the choreography and combination of Chinese folk dance, and the classroom teaching of basic dance choreography techniques. The dance body language and dance body language and Express vividly, reveal the aesthetic enjoyment and ideological influence that dance brings to people, improve students' artistic taste, aesthetic ability and actual choreography ability of various dances, and promote their professional learning on the basis of comprehensively improving their comprehensive artistic quality. To enable students to have more and more comprehensive artistic skills, and to better adapt to the actual needs of the society for the arts education major.

\section{The importance of dance practice teaching}

Dance practice teaching needs to transform the theoretical knowledge of dance into the practical ability of stage performance. The study of this course will be of great significance to the career of art education students to enter the society and engage in dance work. As far as the undergraduate education stage is concerned, Its importance is mainly reflected in the following three aspects.

\subsection{Grow and promote students' interest in learning}

Interest plays an important role in the learning process. It is the basis and motivation of learning and the premise of artistic innovation. At present, in the teaching arrangement of dance practice classes in Nanjing University of the Arts, it pays attention to the basic training of dance technology, emphasizes the complete specification of each dance combination, pays attention to the target basic training assessment and the actual arrangement of dance works. In teaching, it pays attention to thinking, The emotional content and the expression of dance practice thought vocabulary, the classroom teaching is active, and the dance choreography has a strong sense of innovation. Teaching practice shows that cultivating students' interest in stage performances, strengthening the vocabulary expression in dance practice teaching, continuously enriching practical teaching models, innovating teaching methods, and enhancing the interest and ideology of teaching content are to enable students to find confidence in the practice of stage performances. , An important way of destination and achievement.

\subsection{Improve students' comprehensive artistic quality and ability}

At present, the art colleges and universities do not provide many opportunities for students to practice on stage performances, but the dance practice classes in the practice rooms just make up for this deficiency. Art education majors have a good foundation in cultural theory courses, but due to dance training There is not much time, and the foundation of his dance is basically zero. Therefore, his understanding of dance movements, body rhyme and stage performance still has some shortcomings. Through practical teaching, it is possible to enhance the discourse interpretation of body movements and body language, so that students will not increase the understanding and pursuit of dance aesthetics and 
rhythm due to hardship and monotony in actual training. Through the detailed decomposition of dance elements, Improve their professional quality, stimulate their aesthetic emotions, exercise and cultivate their artistic quality, aesthetic taste and independent spirit in a subtle way, and ultimately enhance their ideological and moral consciousness, will bear ability, team spirit and other comprehensive qualities.

\subsection{Promote the reform and innovation of dance practice teaching mode}

Dance practice teaching can consolidate and enhance students' dance knowledge and skills. In the course of practice teaching, teachers can also find problems, take targeted measures, innovate teaching methods, take students as the main body, improve the talent training model, and effectively improve the quality of teaching. Take the 18th-level art education major of the Humanities College of Nanjing University of the Arts as an example. After a year of learning the "Shape and Dance" practical course, they can arrange for the students of Nanjing Corey Primary School under the leadership of the practical teacher in the later stage. In the dance repertoire, actual artistic practice was successfully carried out. In the end, under the general guidance of the teacher, all the students of the 18th art education were the main actors, and the students of Corey Primary School showed their love to assist in the performance, and created a children's dance short drama "Alice's "Dream", as the closing performance at the end of the semester, raised the students' thoughts, emotions, artistic expression and professional quality to a new level, especially their deep understanding of the skit, vivid performance and artistic agility that infected everyone who participated in the viewing. Of students have received a good art education effect. In addition, we also take "dance physical and mental training as an important method of auxiliary training" [1], infiltrating students' daily training.

\section{Problems faced in dance practice teaching}

The problems faced in dance practice teaching generally have the following aspects.

\subsection{The design and arrangement of dance practice teaching is not scientific}

For non-dance professional dance practice teaching courses, there is a tendency to weaken whether it is in the arrangement of the lessons or the time allocation, resulting in fewer dance practice teaching sessions, and the practice of dance courses is taken as an elective course. The selection rate of other majors such as music and painting has not been improved, which affects the overall quality of students. There is still a big gap between the school's capital investment, dance room and other hardware construction, and the actual needs of teachers, and cannot be effectively improved. The quality of the dance practice teaching class. When arranging the teaching plan, full consideration should be given to the academic situation. The dance courses for non-dance majors are only available for one year, and it is impossible to solve the problem of students' "soft opening" in a short time, and it is even impossible to train dance majors according to The direction of the teaching method of gradually advancing from a single element to a composite element can only moderately extract the material training that suits them. In the implementation of the teaching, the teaching materials are prepared from easy to difficult, so that they can be adjusted at any time. Therefore, in a year In the practice of dance teaching, the arrangement of the teaching needs to be done scientifically in accordance with the law of gradual progress in dance teaching.

\subsection{Outdated teaching methods cannot meet modern requirements}

Many colleges and universities still adopt traditional teaching methods in dance practice teaching. The one-way indoctrination in the teaching process is lack of communication and interaction, which affects the enthusiasm and initiative of students in learning. In addition, there is a single teaching method and a lack of modern teaching methods. For example, there is only music but lack of large-scale video playback, which can not make students experience immersive education in the practice room and inspire their artistic inspiration. Traditional teaching methods and methods cannot effectively attract the attention of students, and their educational effects are also unsatisfactory. Students' comprehensive abilities cannot be improved in all aspects, and they cannot satisfy students' pursuit of dance art. In actual teaching, teachers should constantly change teaching methods, improve professional teaching and teaching ability, and be good at transforming theoretical knowledge into students' practical ability. In the arrangement of teaching content, it is necessary to broaden the content of the teaching materials, broaden the students' horizons of knowledge, effectively decompose and teach some classic dance combinations of large-scale dance epics to students, and always pay attention to the simultaneous interpretation and comparison of dance theories and works. On the other hand, colleges and universities should also expand their teaching bases, keep up with the pace of the times, improve social aesthetic education, go out of the school, and cooperate with group art departments and performing arts institutions to create teaching situations for students and provide opportunities 
for students to learn Perfect and improve oneself in the social arena and real social practice. The school should also build its own performing arts theater through various channels and methods to provide students with a practical stage and improve their practical ability.

\subsection{The teaching ability of professional dance teachers needs to be improved}

In the face of constant changes in social needs and the emergence of new industries, dance teachers are also facing new challenges, such as the problem of zero-based dance students in the art education major. There is no way to implement professional dance practice classroom teaching. The teachers themselves Ability is of the utmost importance. How to adapt to this kind of teaching method while seeking change is an emerging problem facing dance teachers. At present, dance teachers in professional colleges are roughly divided into two categories: theoretical teachers and practical teachers. Theoretical teachers are often from theoretical backgrounds and lack practical skills; while some practical teachers emphasize practice and lack deep theoretical research. In particular, some practical teachers have low academic qualifications, weak scientific research capabilities, and lack of theoretical knowledge, which makes it difficult to guarantee the quality of dance practice teaching. In addition, non-dance students have a weak foundation in dance majors and have a strong enthusiasm for dance. However, due to the greater intensity of basic dance practice teaching, the physical development of these students has been formed, and the training is more difficult. The training of students is very difficult. Hard work is a severe test of their endurance and perseverance. Students are afraid of hardship, tiredness, and fear that they will take up too much time and affect their own professional learning. In addition, in the basic training of practical classes, very few students occasionally do not abide by the training rules. Suffering minor injuries, the practice class is sometimes unavoidable from the incomprehension of a few students and the misunderstanding of the parents, which affects the in-depth progress and reform of the practice class. Therefore, for the teacher of dance practice class, it is not to train a professional dancer, but how to stimulate the instinctive reaction of students' body language, creative consciousness and innovative ability. It is necessary to deeply care for each student and to understand them deeply. Understand their differences in their thoughts, emotions and personalities, and strive to cultivate their volitional character, aesthetic cognition, artistic inspiration and physical coordination.

\section{Optimizing strategies for dance practice teaching}

Many colleges and universities attach importance to professional theory courses in dance teaching, but do not pay enough attention to dance practice courses. Under the new historical conditions, it is necessary to further optimize dance practice teaching strategies and mobilize students to actively participate in dance practice teaching ${ }^{[2]}$, improve students' artistic quality in an all-round way, and lay a solid foundation for their future career development.

\subsection{Optimize teaching goals and plans}

Standardize the dance practice syllabus, enrich the teaching connotation, and improve the quality of teaching. It is necessary to build a complete textbook system, especially for the creation of textbooks for zero-based art education, and to penetrate the use of basic knowledge elements of dance. It is necessary to strengthen the basic training of dance practice teaching, and come up with specific teaching plans for students of art education with zero foundation. For example, a single body part cognitive training, hand, head, foot, knee bending and other single element exercises. It can enable students to understand and recognize the basic skills of dance. In the process of dance practice teaching, students should be guided in a rigorous, scientific and reasonable training to stimulate their physical instincts and achieve students' creative consciousness. Teachers should pay attention to the most basic balance and coordination ability of students' posture training. Teachers should create some single fancy style dance combinations as investigation projects. Finally, teachers should also formulate targeted teaching plans for students according to the actual situation of students, and do a good job of reporting and performing practical teaching in each semester. Promote the dance creation of teachers and students through reporting performances, actively strengthen students' creative and innovative ability, and enhance students' selfconfidence and stage cognitive ability in stage performances. In addition. "Introducing regional culture into dance teaching in local colleges and universities will help strengthen the creative transformation and innovative development of local excellent traditional culture and art resources in local colleges and universities." ${ }^{[3]}$ It is also necessary to ensure teaching time, clarify practical teaching tasks, and do a good Implementation of a teaching task.

\subsection{Innovative teaching implementation mode}

It is necessary to use modern teaching methods, photoelectric and media facilities to enhance the charm of dance practice classes. It is necessary for students to experience the effective expressions, thoughts and feelings of dance 
aesthetics, and to help students understand and understand the truth, goodness, beauty and falsehood in human social life contained in dance practice works. In dance practice teaching, it is necessary to highlight the essential connotation of dance, give play to the guiding role of teachers and the main role of students, cultivate students' interest in learning, and systematically teach the essence of dance practice training and the value meaning of dance creation prototypes. Learning performance, training students' higher artistic appreciation ability, inspiring students' desire to learn in dance practice teaching ${ }^{[4]}$, allowing students to truly experience the true feelings expressed in dance works, and improving students' good artistic quality and performance ability. Teachers should give full play to their artistic imagination and implement effective education for students through the arrangement of works. It is necessary to use a variety of teaching methods to carry out teaching, and effectively mobilize the enthusiasm and subjective initiative of both teaching and learning. "In the process of dance practice teaching, students should be trained in a strict, scientific and reasonable manner in time." ${ }^{[5]}$ Teachers should teach by preaching and teach others tirelessly, so that students can master the essentials and techniques of various dance movements. You can study and train in groups. Students learn and help each other, discuss and improve together, and truly master the basic training elements such as dance body language coordination, body control, and movement stability, thereby effectively improving students' dance practice ability.

\subsection{Enhance the professional teaching ability of dance teachers}

It is necessary to change the evaluation mechanism for dance practice teachers and reduce the proportion of scientific research theoretical articles in the evaluation of practice teachers. It is necessary to strengthen the training of dance teachers, send more first-line young teachers to study abroad, participate in various practical teaching conferences at home and abroad, and adopt the method of inviting in, hire experts in dance practice to pass on the lessons and send treasures to the school to improve the teacher's practice teaching ability. In practical teaching, teachers should teach students in accordance with their aptitude, carefully understand their academic conditions, and formulate Zhou Xiang's teaching plan for teaching. Dance is not a mechanical physical movement. Teachers must master the soul of dance, understand the expressiveness of dance, attach importance to the training of students to convey thoughts and feelings through dance, and cultivate students' artistic comprehension ability. It is necessary to actively organize, support and encourage students to participate in various forms of theatrical performances inside and outside the school, combine students' classroom dance teaching with practical activities, master dance knowledge and movement skills through real stage art practice, and master more practical experience to establish Self-confidence in stage art performance. Schools with conditions can hire famous dancers at home and abroad as consultants for practice courses to guide the innovation of dance practice courses through the integration of macro and micro levels.

\section{Conclusion}

As far as the status quo of dance practice courses for art education majors is concerned, first of all, the school must effectively put this work in its place, "attract sufficient attention, ensure sufficient funds and manpower" ${ }^{[6]}$, formulate and issue implementation opinions to ensure the effectiveness of practical teaching. Secondly, it is necessary to optimize the teaching objectives and teaching plans, stimulate students' interest in learning, and constantly innovate the working mode of practical teaching. Third, it is necessary to continuously improve the comprehensive quality of teachers, especially the level of cultural knowledge, so that dance practice teaching can truly be combined with theoretical innovation.

Acknowledgments

This article is a key project of Jiangsu University's philosophy and social science research project "Innovative Research on the Teaching Model of Socialist Core Values in Colleges and Universities in the New Media Era" (Project Number: 2018SJZDI009), Jiangsu Social Science Research Fund Project "Recognition Education Research on Socialist Core Values in Colleges and Universities in the New Media Era "(19MLD002) phased results.

\section{References}

[1] Wu Xinyi. The application of physical and mental training in dance practice teaching. Journal of Beijing Dance Academy. 2016; (4).

[2] Wu Hong. Discussion on the construction of the practice teaching system of dance majors in colleges and universities in the new era. Tomorrow's Fashion. 2018; (13): 199.

[3] Liu Ya. Research on the dance teaching mode of "promoting teaching by competition" in local colleges and universities. Art Criticism. 2019; (14). 
[4] Yang Jiawei. Reform and construction of the practice teaching system of dance performance in art colleges and universities. Curriculum Education Research. 2018; (27): 205-206.

[5] Liu Yang. An analysis of dance practice teaching strategies in sports colleges. Contemporary Sports Science and Technology. 2018; (32).

[6] Wu Xumin. Problems and optimization strategies in dance practice teaching. Drama House. 2017; (17). 